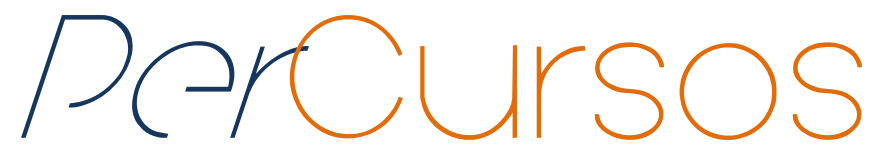

\title{
Processo de reconhecimento e certificação de saberes escolares de trabalhadores: orientações teórico-metodológicas ${ }^{1}$
}

\begin{abstract}
Resumo
Este artigo apresenta o histórico e os resultados do projeto piloto "Reconhecimento e Certificação de Saberes Escolares de Trabalhadores", executado entre abril e julho de 2014. Tal projeto teve como objetivo reconhecer e certificar saberes escolares em nível de Ensino Fundamental, de trabalhadores da área de Turismo, Hospitalidade e Lazer, previamente selecionados, possibilitando o ingresso destes sujeitos no Programa Nacional de Integração da Educação Profissional com a Educação Básica na modalidade de Educação de Jovens e Adultos - PROEJA, especificamente no Curso Técnico em Guia de Turismo PROEJA-CERTIFIC. Este trabalho se caracterizou como pesquisa-ação, orientando-se teórica e metodologicamente pelas concepções freireanas de educação, pelos princípios e diretrizes da Educação Popular, pelos Parâmetros Curriculares Nacionais para o Ensino Fundamental (PCNs), pelas diretrizes da Rede Nacional de Reconhecimento de Saberes Profissionais (CERTIFIC) e da Educação de Jovens e Adultos. Foram certificados doze sujeitos participantes do processo, $100 \%$ dos inscritos. Neste texto, apresentam-se orientações teórico-metodológicas que podem contribuir e orientar experiências similares de certificação de trabalhadores.
\end{abstract}

Palavras-chave: Certificação de trabalhadores; Educação de jovens e adultos; Educação popular; Reconhecimento de saberes escolares.

\author{
Claudia Hickenbick \\ Mestre em Educação pela \\ Universidade Federal do Paraná - \\ UFPR. Professora do Instituto \\ Federal de Santa Catarina - IFSC. \\ Brasil \\ claudia@ifsc.edu.br
}

\section{Elenita Eliete de Lima Ramos}

Doutora em Educação Científica e Tecnológica pela Universidade

Federal de Santa Catarina - UFSC. Professora do Instituto Federal de Santa Catarina - IFSC. Brasil elenita@ifsc.edu.br

Miriam de C. C. M. Mattos
Mestre em Ciência da Informação
pela Universidade Estadual
Paulista - UNESP - SP.
Professora do Instituto Federal
de Santa Catarina - IFSC.
Brasil
miriammattos@gmail.com

\footnotetext{
${ }^{1} \mathrm{O}$ artigo discute o Projeto Piloto de Reconhecimento e Certificação de Saberes Escolares de Trabalhadores do Instituto Federal de Santa Catarina - IFSC.
} 


\title{
Procedure for recognition and certification of knowledge school workers: theoretical and methodological guidelines
}

\begin{abstract}
This paper presents the history and the partial results of the pilot project "Recognition and Certification of School Knowledge of Workers" done from April to July 2014. This project intended to recognize and certify primary education knowledge of pre-selected tourism, hospitality and leisure workers, allowing the entry of these people into a high school that is integrated to professional education in the form of Youth and Adult Education, specifically theProeja Certific Regional Tourism Guide to Santa Catarina. This project was characterized as action research, seeking to develop knowledge and understanding as part of practical work. It was theoretically and methodologically guided by Frierean educational conceptions, the principles and guidelines of Popular Education, the National Curriculum Standards for Primary Education, the guidelines of the National Network of Professional Knowledge Recognition (Certific) and Youth and Adult Education. Twelve project participants were certified, which represents $100 \%$ of those selected. In this paper, we present theoretical and methodological guidelines that can help and guide similar experiences for the certification of workers.
\end{abstract}

Keywords: Certification of workers; Youth and adult education; Popular education; Recognition of school knowledge.

\section{Para citar este artigo:}

HICKENBICK, Claudia; RAMOS, Elenita Eliete de Lima; Mattos, Miriam de C. C. M. Processo de reconhecimento e certificação de saberes escolares de trabalhadores: orientações teóricometodológicas. Revista PerCursos. Florianópolis, v. 16, n.31, p. 28 - 58, maio/ago. 2015.

\section{DOI: $\mathbf{1 0 . 5 9 6 5 / 1 9 8 4 7 2 4 6 1 6 3 1 2 0 1 5 0 2 8}$}

http://dx.doi.org/10.5965/1984724616312015028 
"Ninguém ignora tudo. Ninguém sabe tudo. Todos nós sabemos alguma coisa. Todos nós ignoramos alguma coisa. Por isso aprendemos sempre."

Paulo Freire

"No início não sabíamos ao certo como fazer, mas sabíamos que era preciso fazer[...]"

Coordenação do Projeto Piloto

\section{Apresentação}

O reconhecimento e validação de saberes tem sido, nos últimos anos, uma prática corrente em vários países ${ }^{2}$ como alternativa de empoderamento ${ }^{3}$ de trabalhadores frente às exigências sociais e mercadológicas de qualificação profissional. No Brasil, as experiências de validação de saberes profissionais dos trabalhadores têm sido consideradas no seio do movimento popular e sindical, que apregoa o reconhecimento dos saberes como um direito do trabalhador (FISCHER, 2009).

Tal procedimento fundamenta-se na compreensão da possibilidade de aprendizagem em múltiplos espaços e situações, formais, informais ou não formais, o que implicaria na criação de condições para fazer emergir e, consequentemente, reconhecer os conhecimentos e experiências adquiridos bem como as aprendizagens realizadas ao longo da vida.

O descompasso que há em nosso país entre o desenvolvimento científico e tecnológico e o elevado número de habitantes não escolarizados, seja em função das desigualdades sociais, seja como fruto de uma educação bancária $^{4}$ que pouco reconhecia da experiência dos sujeitos nos

\footnotetext{
${ }^{2}$ Reino Unido - Qualifications and Credit Framework (QCF), Portugal - o Sistema de Reconhecimento, Validação e Certificação de Competências - RVCC. Os artigos de (STEFFEN, 2009) e (CUNHA; LIMA, 2012) apresentam mais detalhamentos dessas experiências.

${ }^{3} \mathrm{O}$ tema de empoderamento, dentro da concepção Freireana, é inspirado principalmente nas leituras de Gramsci, baseadas no marxismo. A palavra empowerment é de origem inglesa e significa "dar o poder" a alguém para realizar uma tarefa sem precisar da permissão de outra pessoa. Em Paulo Freire, esse empoderamento é a ação do educador, grupo ou instituição empoderada que realiza, por si mesma, as mudanças e ações que a levam a evoluir e se fortalecer.

${ }^{4}$ A educação bancária é concebida por Paulo Freire como sendo uma educação como prática de dominação. Em lugar de comunicar-se, o educador faz comunicados e depósitos e a única ação que se oferece aos educandos é a de receber os depósitos e arquivá-los. (RAMOS, 2011)
} 
processos de aprendizagem, tem impulsionado políticas que possam contribuir com novas alternativas de escolarização e qualificação profissional, dentre elas, a criação do PROEJA ${ }^{5}$. (BERGER, HICKENBICK e RAMOS, 2014, p. 4)

Compartilhando dessa concepção, o Instituto Federal de Educação, Ciência e Tecnologia de Santa Catarina - IFSC, reconheceu a necessidade de buscar alternativas, como a experiência aqui relatada, que visem a valorização da experiência de trabalhadores por meio de um processo de Certificação de Saberes a fim de possibilitar o acesso desses mesmos trabalhadores a um curso do PROEJA articulado ao CERTIFIC ${ }^{6}$.

Na perspectiva de elevar a escolaridade do trabalhador e proporcionar-lhe uma formação profissional, o IFSC vem ofertando, desde 2006, cursos do Programa Nacional de Integração da Educação Profissional com a Educação Básica na modalidade de Educação de Jovens e Adultos - PROEJA. E, desde 2010, a instituição oferta o reconhecimento de saberes profissionais de trabalhadores no âmbito da Rede CERTIFIC.

Concebido e executado pela Comissão Permanente de Integração dos Programas Sociais - CIPS, formada pelas coordenações de Reconhecimento de Saberes e do PROEJA, e articulada à Pró-Reitoria de Extensão, o projeto de reconhecimento de saberes escolares materializou o desejo de Pró-reitoria de Ensino do IFSC, de que a instituição seja acessível às pessoas que não tiveram a escola como um caminho natural, ou seja, o público da Educação de Jovens e Adultos - EJA. Este projeto buscou se aproximar de alguns princípios da Educação Popular, tais como a constituição de uma equipe autogestionária para elaborar e executar o projeto; a reflexão sobre a prática e publicização dos resultados, materializada neste artigo.

\footnotetext{
${ }^{5}$ Programa Nacional de Integração da Educação Profissional com a Educação Básica na modalidade de Educação de Jovens e Adultos (PROEJA).

${ }^{6}$ A Rede Nacional de Certificação Profissional (CERTIFIC) traz de volta para a escola trabalhadores que aprenderam uma profissão sem terem adquirido seus conhecimentos na educação formal. (IFSC, 2014)
} 
A CIPS, que é vinculada a Pró-reitoria de Ensino do IFSC, vem centrando esforços no sentido de integrar o PROEJA ao CERTIFIC. Para tanto, concebeu e coordena quatro projetos-piloto que objetivam concretizar esta integração ${ }^{7}$.

Por conta de uma demanda específica de um destes projetos (Técnico em Guia de Turismo, ofertado pelo Campus Florianópolis - Continente), qual seja, o fato de que os potenciais alunos do curso não tinham escolaridade para ingressarem no curso técnico houve a necessidade de criação de um quinto Projeto Piloto, sendo este o foco deste artigo - "Projeto Piloto de reconhecimento e certificação de saberes escolares de trabalhadores da área de turismo, hospitalidade e lazer", ocorrido entre os meses de abril e julho de 2014 .

\section{Contextualizando o problema de pesquisa}

No ano de 2011, o câmpus Florianópolis-Continente (CFC) identificou que Florianópolis possuía trabalhadores informais atuando como "guias de turismo", numa relação política e social complexa marcada por equívocos e entraves históricos. Enquanto instituição educacional, pautada na pesquisa, ensino e extensão, com vocação especial à inclusão cidadã, o IFSC deu início a uma agenda de reuniões com a Secretaria Municipal de Turismo, Cultura e Esportes (SETUR), com representantes do Ministério do Turismo e com alguns representantes do grupo de trabalhadores em questão.

No ano seguinte, o CFC deu início aos trabalhos para a oferta do processo de reconhecimento de saberes profissionais dos trabalhadores informais " guias de turismo", alguns deles atuando há três décadas em Florianópolis. Estes trabalhos transcorreram durante todo o ano letivo. Entretanto, no início de 2013, uma decisão tomada em reunião entre CFC e SETUR interrompeu este processo, com a justificativa da inadequação da escolaridade do grupo, uma vez que alguns não tinham o Ensino Médio,

\footnotetext{
7 Projetos desenvolvidos pelas EIPS - Equipe de Integração dos Programas Sociais (campus) vinculadas à CIPS (reitoria). EIPS Itajaí: Proeja FIC Integrado ao CERTIFIC na área de pesca; EIPS Jaraguá do Sul: Proeja Técnico integrado ao CERTIFIC na área têxtil; EIPS Florianópolis-Continente: Proeja Técnico integrado ao CERTIFIC na área de turismo hospitalidade e Lazer; EIPS Garopaba: Proeja FIC Integrado ao CERTIFIC na área de turismo hospitalidade e lazer.
} 
nível exigido para a certificação dos guias de turismo, outros, sequer, o Ensino Fundamental. A esta carência de nível de escolaridade a CIPS respondeu com a concepção e oferta do projeto que é objeto do presente artigo.

Com o intuito de ampliar o número de pessoas atendidas, decidiu-se contemplar também trabalhadores e trabalhadoras que exerciam a função de merendeiros(as) ${ }^{8}$ nas escolas do município de Florianópolis. Tal decisão surgiu quando o Coordenador da EJA da Secretaria Municipal de Florianópolis, Daniel Berger Godinho, declarou poder haver, entre esses cozinheiros e cozinheiras, alguns em condições de terem reconhecidos seus saberes. Segundo ele, em 2014 a Grande Florianópolis possuía "69 mil pessoas com mais de 18 anos que não conseguiram completar o Ensino Fundamental”. Entre estas pessoas estão as que cozinham nas escolas municipais, o que faz lembrar a canção-denúncia de Zé Geraldo, intitulada Cidadão: “Tá vendo aquele colégio moço, eu também trabalhei lá [...]”, em que o compositor canta a sina de um operário que constrói edifícios e colégios nos quais nunca poderá morar ou estudar.

É importante destacar que este Projeto de Reconhecimento de Saberes Escolares teve como objetivo maior conduzir os trabalhadores a um curso técnico na área em que atuam, possibilitando a continuidade da escolarização interrompida. Portanto, a intenção não foi a de atender a grupos aleatórios, mas sujeitos que poderiam percorrer seus itinerários formativos no IFSC, neste caso, um curso do PROEJA de nível técnico integrado ao CERTIFIC.

Como a instituição oferta anualmente o curso Técnico em Gastronomia - PROEJA, justifica-se serem estes os trabalhadores escolhidos para terem seus conhecimentos reconhecidos.

Este trabalho buscou responder aos seguintes questionamentos: quais são as etapas necessárias para um processo de reconhecimento e certificação de saberes escolares de trabalhadores e quais teorias e metodologias podem sustentá-lo?

\footnotetext{
${ }^{8}$ A denominação cozinheiras é utilizada a partir da prática desempenhada pelas trabalhadoras em questão, embora, em seus registros profissionais sejam identificadas como merendeiras.
} 


\section{Metodologia}

A metodologia utilizada nessa pesquisa possui elementos de uma pesquisa-ação, que é caracterizada por ser um processo de aprendizagem para todos os participantes, e a separação entre sujeito e objeto de pesquisa é superada. De fato, o processo de aprendizagem durante o desenvolvimento dessa pesquisa envolveu a todos: tanto os trabalhadores que estavam participando do processo para reconhecer seus saberes, quanto os educadores/pesquisadores, por se desafiarem a buscar elementos para executar algo novo que não se aprende nos cursos de Pedagogia ou nas Licenciaturas.

$O$ pesquisador neste contexto torna-se um praticante social que intervém numa situação com o fim de verificar se um novo procedimento é eficaz ou não. Outra característica da pesquisa-ação é que esta é situacional, ou seja, procura diagnosticar um problema específico numa situação também específica, com o fim de atingir uma relevância prática dos resultados (ENGEL, 2000).

Ressalta-se que a metodologia utilizada para a execução desse projeto se relacionou diretamente com os princípios e diretrizes para a educação popular nas políticas públicas ${ }^{9}$ a qual se constituiu de cinco etapas, descritas a seguir:

\section{$1^{\text {a }}$ Etapa - formação da equipe de trabalho}

A equipe de pesquisadores/educadores, para atuar na construção e aplicação desse projeto, foi selecionada por meio de edital púbico e formada por professores das disciplinas que compõem o Ensino Fundamental com experiência na Educação de Jovens e Adultos e mais três sistematizadoras com experiência na Educação Popular. Esta se caracterizou como uma equipe autogestionada, e teve a função de conceber teórica e metodologicamente todo o processo de reconhecimento de saberes escolares.

Segundo Albuquerque (2003, p. 20-21), a autogestão possui um caráter multidimensional (social, econômico, político e técnico) e refere-se a uma forma de

\footnotetext{
${ }^{9}$ Diretrizes estas apresentadas no documento "Marco de Referência da Educação Popular para as Políticas Públicas" (2014).
} 
organização da ação coletiva. A autogestão tem uma dimensão social, pois "[...] deve ser percebida como resultado de um processo capaz de engendrar ações e resultados aceitáveis para todos os indivíduos e grupos que dela dependem".

\section{$2^{\mathrm{a}}$ Etapa - construção do projeto}

Esta etapa teve como objetivo a apropriação, pela equipe executora, do préprojeto previamente elaborado pela coordenação da CIPS, e do referencial teórico, que poderia ser ampliado ou modificado se assim a equipe achasse necessário. Nessa etapa, as atividades foram intercaladas por encontros coletivos e atividades de estudo individuais.

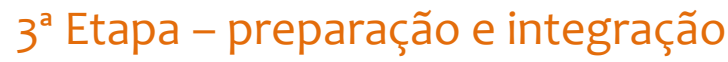

Nesta etapa as reuniões coletivas foram intensificadas, pois era necessário definir como seria a integração dos pesquisadores/educadores com os trabalhadores, os guias e as cozinheiras, assim como os instrumentos que seriam utilizados para o diagnóstico dos saberes. Partindo-se das experiências do grupo de pesquisadores/educadores, foram escolhidos os instrumentos que seriam utilizados para identificar o perfil socioeconômico dos trabalhadores estudantes: um questionário construído com base no CERTIFIC e uma dinâmica coletiva de apresentação. Tanto o questionário como a dinâmica, esta última gravada em áudio, foram aplicados no primeiro encontro entre os estudantes e os educadores/pesquisadores. Os questionários e áudios se mostraram um material bastante rico para esta pesquisa, pois possibilitaram conhecer os sujeitos com os quais a equipe iria trabalhar.

\section{$4^{a}$ Etapa - preparação e aplicação das atividades: diagnóstico por disciplina}

Após longos debates acerca das metodologias a serem utilizadas no processo de certificação, o grupo optou pela realização de três atividades coletivas interdisciplinares: 
Relato de experiência - teve por objetivo reconhecer as experiências de cada indivíduo na perspectiva da construção de conhecimentos, bem como conhecer melhor o estudante trabalhador. Esta atividade envolveu todos os educadores/pesquisadores e foi desenvolvida com os dois grupos separadamente (cozinheiras e guias). A atividade foi guiada por um roteiro que permitiu conhecer um pouco da vida laboral desses sujeitos e consequentemente alguns dos conhecimentos desenvolvidos nesse espaço de trabalho. Estes relatos foram gravados e transcritos, constituindo-se em material fértil para a identificação de saberes e para a elaboração de outras atividades que deveriam ser desenvolvidas em outro momento do processo.

Diário de classe - fundamentado na experiência da EJA do Município de Florianópolis, foi trazido para o grupo por uma das educadoras/pesquisadoras que já havia feito uso do instrumento na Rede Municipal de Ensino. O Diário se constituiu como um espaço em que o aluno pôde se expressar livremente por meio da escrita em um “caderno diário”, e se revelou um importante instrumento de interação entre educadores e estudantes, já que eram recolhidos e lidos semanalmente.

Saída de Campo - visita à diferentes pontos da região do Centro Histórico de Florianópolis, com o objetivo de provocar reflexões acerca das transformações urbanas e das relações entre patrimônio edificado, memória e identidade. A saída de campo permitiu reflexões sobre as remodelações urbanísticas ocorridas no município durante o século XX e a identificação das divisões sociais, espaciais e culturais da cidade. O trajeto foi realizado a pé e teve duração aproximada de 3 horas. Os locais foram escolhidos conforme a demanda de cada disciplina.

Além das atividades coletivas acima descritas, foram desenvolvidas atividades específicas por disciplinas. Estas atividades foram estruturadas de forma a possibilitar aos professores avaliar os conhecimentos dos trabalhadores acerca dos conteúdos do Ensino Fundamental em cada disciplina, sem, necessariamente, aplicar uma avaliação. Foram realizados dezesseis encontros, ao longo de quatro semanas. Estes encontros aconteciam de segunda a quinta-feira no período noturno. As sextas-feiras foram utilizadas para avaliação do processo por toda a equipe de pesquisadores. 


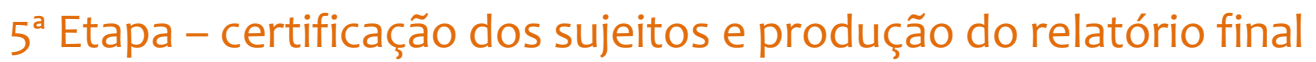

Após a finalização das atividades de diagnóstico houve uma avaliação coletiva do processo em que participaram todos os envolvidos no projeto. Para a construção do diagnóstico individual de cada trabalhador-estudante foi realizado um conselho de classe em que foi possível refletir e analisar o processo de diagnóstico coletivo e individual.

Cabe lembrar que o reconhecimento dos saberes escolares ocorreu de forma processual, ou seja, houve mudanças no planejamento inicial em função de demandas decorrentes do andamento do processo. Os certificados, entregues aos participantes em cerimônia de certificação do Ensino Fundamental, foram acompanhados por um documento no qual se descreveu as habilidades identificadas e as dificuldades apresentadas. Esse documento é de fundamental importância para que os docentes da próxima etapa educativa possam estar cientes de possíveis fragilidades que devam ser melhor trabalhadas nessa fase posterior.

\section{Fundamentação teórica}

Os Parâmetros Curriculares Nacionais para Ensino Fundamental (PCNs), principal referencial para a Educação Básica no país, foi o primeiro documento que apresentou abertura legal e teórica ao grupo de educadores/pesquisadores. Apesar de suas limitações ${ }^{10}$, o documento reconhece a complexidade da prática educativa, sinalizando a possibilidade de "rever objetivos, conteúdos, formas de encaminhamento das atividades, expectativas de aprendizagem e maneiras de avaliar" (BRASIL, MEC, p. 10).

Segundo os PCNs, para a estruturação da intervenção educativa é fundamental distinguir o nível de desenvolvimento real do potencial do sujeito.

O nível de desenvolvimento real se determina como aquilo que o aluno pode fazer sozinho em uma situação determinada, sem ajuda de ninguém. O nível de desenvolvimento potencial é determinado pelo que

\footnotetext{
${ }^{10}$ Os PCNs são pensados para atender crianças e jovens, que frequentam a escola na idade dita regular.
} 
o aluno pode fazer ou aprender mediante a interação com outras pessoas, conforme as observa, imitando, trocando idéias com elas, ouvindo suas explicações, sendo desafiado por elas ou contrapondo-se a elas, sejam essas pessoas o professor ou seus colegas. (BRASIL, 1997, p. 38 , grifos nosso)

Coerente com uma prática educativa adequada às necessidades sociais, políticas, econômicas e culturais da realidade brasileira, os PCN's norteiam em seus princípios uma visão de educação para a cidadania. Nessa formação, destaca-se a "relevância de discussões sobre dignidade do ser humano, a igualdade de direitos, a recusa categórica de formas de discriminação, a importância da solidariedade e respeito" (BRASIL, 1997, p. 27).

Em síntese, o objetivo da escola seria formar um aluno capaz de interferir criticamente na realidade para transformá-la. Esse empoderamento permitiria aos alunos serem protagonistas no complexo mundo atual, com competência e consciência profissional. Estes aspectos dos PCNs dialogaram diretamente com o projeto, pois buscou-se identificar os saberes dos participantes a partir da problematização de questões sociais atuais e daquelas enfrentadas ao longo da vida.

Destaca-se aqui a dialogicidade do processo, capaz de possibilitar a participação do aluno concomitantemente com a intervenção do professor. Ao mesmo tempo em que reconhece a importância dos saberes elaborados socialmente, entende que este conteúdo está a serviço da inserção do aluno nas questões sociais de modo a favorecer a compreensão e a intervenção nos fenômenos sociais e culturais em que vive.

Assim, o conhecimento é uma interação constante entre o saber escolar e os demais saberes, entre o que o aluno aprende na escola e o que ele traz para a escola estando em jogo capacidades de relação interpessoal, cognitivas, afetivas, motoras, estéticas e de inserção social. (BRASIL, PCNs, 1997)

O desenvolvimento de capacidades, como as de relação interpessoal, as cognitivas, as afetivas, as motoras, as éticas, as estéticas de inserção social, torna-se possível mediante o processo de construção e reconstrução de conhecimentos. Essa aprendizagem é exercida com o 
aporte pessoal de cada um, o que explica por que, a partir dos mesmos saberes, há sempre lugar para a construção de uma infinidade de significados, e não a uniformidade destes. Os conhecimentos que se transmitem e se recriam na escola ganham sentido quando são produtos de uma construção dinâmica que se opera na interação constante entre o saber escolar e os demais saberes, entre o que o aluno aprende na escola e o que ele traz para a escola, num processo contínuo e permanente de aquisição, no qual interferem fatores políticos, sociais, culturais e psicológicos. (BRASIL, PCNs, 1997, p. 34)

É importante registrar que este trabalho se fundamentou, em grande medida, na metodologia do CERTIFIC, um processo voltado para trabalhadores que aprenderam uma profissão sem nunca terem frequentado cursos da Educação Profissional. Por meio desse processo, os trabalhadores mostram o quanto dominam de sua profissão, podendo ser certificados pelas habilidades demonstradas.

A EJA também foi foco dos estudos iniciais, já que é necessário compreendê-la como uma modalidade de ensino específica, e como tal deve ser tratada, considerando, sobretudo, as especificidades do público que a frequenta. Conforme Soares, Giovanetti e Gomes (2005):

Se qualquer atuação acadêmica e de pesquisa na área das ciências humanas exige posicionamentos políticos e sensibilidade para com os processos de humanização e desumanização vividos pelos sujeitos, aqueles que se dedicam ao campo da Educação de Jovens e Adultos carregam em si mesmos e nas investigações que realizam uma maior responsabilidade social, política e acadêmica de compreender, interpretar, descrever, refletir e analisar as trajetórias, histórias de vida, saberes, ensinamentos e conhecimentos produzidos pelas pessoas jovens e adultas. (SOARES, GIOVANETTI; GOMES, 2005, p. 7 e 8)

Esses mesmos autores ainda afirmam ser a EJA um campo político denso que carrega consigo “o rico legado da Educação Popular”.

Com relação às contribuições da Educação Popular nesse projeto, destaca-se o Marco de Referência da Educação Popular para Políticas Públicas publicado no ano de 2014 que traz categorias importantes para orientar as experiências populares e 
institucionais: dialogicidade, amorosidade, conscientização, transformação da realidade e do mundo, partir da realidade concreta, construção do conhecimento, pesquisa participante e sistematização de experiência do conhecimento.

A dialogicidade esteve presente no diálogo entre os educadores, entre os trabalhadores, e entre educadores e trabalhadores, tecendo uma teia entre a ação e a reflexão, "possibilitando a troca de significados e o aprofundamento na compreensão dos elementos constitutivos da realidade, oportunizando a reconstituição simbólica do real, e permitindo a construção de significados comuns” (BRASIL, 2014, p. 37).

Para Freire (2005), o diálogo é o lugar do encontro entre educando e educadores. “Neste lugar de encontro, não há ignorantes absolutos, nem sábios absolutos: há homens que, em comunhão, buscam saber mais" (FREIRE, 2005, p. 93).

A amorosidade, segundo Freire (2005), está presente na reflexão homem-mulhermundo, em que o diálogo se apresenta permeado pela humildade e esperança. "Mas este compromisso, porque amoroso, é dialógico [...] como ato de liberdade não pode ser pretexto de manipulação, senão gerador de outros atos de liberdade" (FREIRE, 2005, p. 92).

A conscientização consiste no desenvolvimento crítico da tomada de consciência, um compromisso histórico. Para Freire(2005), esta unidade dialética constitui, de maneira permanente, o modo de ser ou de transformar o mundo que caracteriza homens e mulheres e que estes assumam o papel de sujeitos que fazem e refazem o mundo.

Assim, buscou-se identificar no percurso metodológico desse projeto-piloto alguns princípios da Educação Popular ${ }_{11}$. São eles:

\section{O cenário}

Parte da realidade concebida como um espaço que integra o sonho e a realidade, é o "esperançar" onde o sonhar é a força motriz, sempre com os pés no chão da realidade, estimulando o processo a partir da história dos sujeitos, da comunidade na perspectiva da construção coletiva e da

\footnotetext{
${ }^{11}$ Estes são expostos no documento “Marco de Referência da Educação Popular” (2014).
} 
troca dos saberes. [...] Neste sentido, registrar a primeira conversa e contato, sistematizar o que se realiza é primordial na proposta metodológica da Educação Popular. (BRASIL, 2014, p. 56)

No projeto, o cenário se constituiu na volta dos trabalhadores aos bancos escolares e a materialização de um sonho, e o "esperançar" pode ser percebido nos depoimentos dados pelos sujeitos ao final do processo. Na fala dos Guias ${ }^{12}$ : um sonho de mais de 20 anos, e a esperança de enfim poder exercer a profissão de forma legalizada. Uma luta de ser alguém. Alguém, somos. Mas sem um papel assinado, ninguém é ninguém. Tem que ter o papel do saber regularizado. [...] Aí tu podes falar: eu sou esse alguém. (trabalhador 1)

Na fala da trabalhadora 2: Para mim isso aqui, tenho certeza que, abriu uma janela. Eu sempre sonhava em dar continuidade aos meus estudos. Isso aqui foi uma polida na minha vida. Abriu a porta e disse: vai! E daqui pra frente que eu vou dar continuidade aos meus estudos.

Para as cozinheiras, esse sonho se expressou na melhora da autoestima, numa injeção de ânimo: Quando você para de sonhar, você precisa de alguma coisa que te dê ânimo. E esse projeto foi a injeção de ânimo pra seguir em frente. Eu sei que cada um aqui tem sonhos... e eu não digo janela, porque eu não gosto de pular janela, mas foi uma porta e tanto! (trabalhadora 2)

Uma injeção de ânimo, para mim foi de autoestima, porque eu pensei que não era nada e hoje eu sei que sou. Demorou um tempo, mas aprendi bastante coisa. Parece que me tiraram do meio do nada, da minha casinha, e me colocaram no meio da cidade. (trabalhadora 1)

Quanto à história dos sujeitos, parte delas foi conhecida nos primeiros encontros, chamados de acolhimento. As falas dos trabalhadores foram registradas em áudio que somados à aplicação de um questionário, apresentaram elementos fundamentais para o projeto, que buscou utilizar ao máximo os elementos da realidade dos participantes.

\footnotetext{
${ }^{12}$ As escritas em itálico são transcrições das gravações das falas dos trabalhadores que participaram do projeto, os guias e as cozinheiras.
} 
Este deve explicitar o sonho e, para isso mobilizar e articular parceiros, envolver os(as) sujeitos políticos para o momento do encontro é essencial na Educação Popular. Este espaço deve apontar a relação entre governo e sociedade civil, movimentos sociais, grupos organizados, numa pactuação contínua e sistemática em torno do que podem construir e gerenciar juntos. (BRASIL, 2014, p. 57)

O projeto nasceu do diálogo entre os trabalhadores que exerciam as suas funções de forma ilegal e entre duas instituições públicas: o Instituto Federal de Educação, Ciência e Tecnologia de Santa Catarina - IFSC e a Prefeitura Municipal de Florianópolis - PMF. Ao mesmo tempo, ao selecionar educadores/pesquisadores, teve como princípio contratar pessoas que conhecessem o trabalho na Educação Popular e possuíssem experiências na EJA. É importante ressaltar que na equipe havia mais pessoas com experiência na EJA do que na Educação Popular.

Também foram mapeadas e estudadas experiências exitosas, como a experiência desenvolvida pela Universidade Federal de Santa Catariana - UFSC e o Movimento Sem Terra (MST) por meio do Programa Nacional de Educação na Reforma Agrária PRONERA. Este programa tem por objetivo implementar ações educativas para os povos do campo, em especial para os assentados e acampados da reforma agrária. A experiência da UFSC, MST e PRONERA fundamentou-se metodologicamente na Pedagogia da Alternância e teoricamente na Teoria dos Complexos de Estudos para atividades com agricultores assentados.

A pedagogia da alternância surgiu em 1935, na França, organizada como uma proposta educativa de um conjunto de famílias camponesas que buscavam uma forma diferenciada de educação para seus filhos que tivessem tempos educativos em conformidade com os tempos produtivos do campo, garantindo a permanência das crianças e jovens do campo. Ao mesmo tempo, consistia em uma proposta de gestão compartilhada entre as famílias, organizando uma metodologia pedagógica da 
alternância, ou seja, alternando períodos de formação na escola, na família e na comunidade (CISNEROS, 2013, p. 44).

De acordo com Dalmagro (2014), a experiência pautou-se no compromisso com a superação das condições difíceis em que vive a classe trabalhadora e a construção de novos patamares da vida social, buscando fundamentar-se teoricamente na Pedagogia Histórico Crítica, na proposta pedagógica do Setor de Educação do MST e dos Complexos de Estudo da Pedagogia Socialista Russa.

Segundo a autora,

Na experiência russa, os Complexos são entendidos como "a complexidade concreta dos fenômenos, tomados da realidade e unificados ao redor de um determinado tema ou idéia central" (NarKomPros, 1924, apud FREITAS, 2009, p. 36). A definição do tema de estudo não ocorre apenas pela aproximação à realidade do educando, mas pela centralidade social que a questão comporta. Na perspectiva materialista histórica dialética a realidade é complexa, constituindo-se como totalidade. Local e geral se encontram em relações recíprocas e interdependentes. Para Freitas (2009, p. 36), "a complexidade concreta dos fenômenos remete à vida, e esta à questão do trabalho". Os Complexos são então, para esse autor, uma tentativa de superação da escola verbalista clássica, buscando a unidade entre teoria e prática. Nesse sentido, o Complexo não é apenas um "tema”, mas a articulação entre a atualidade, a auto-organização e o trabalho, outros conceitos chaves da experiência russa. (DALMAGRO et al, p.4 e 5, 2014)

“Apesar de ter sido muito engrandecedor para o grupo conhecer a experiência, a proposta se distanciava um pouco do projeto proposto pelo IFSC, pois sua estrutura se assemelhava muito com um processo de ensino e não de reconhecimento e certificação" (INSTITUTO, 2014, p. 4).

\section{Espaço de problematização}

Este define os objetos da ação, fomenta a reflexão e o diálogo questionando as causas dos fatos, desmonta a visão mágica ao propor falar dos problemas cotidianos com a comunidade, refletindo em torno 
da situação conjuntural e de suas causas econômicas, políticas, culturais, sociais, etc. [...] Pode-se dizer que a leitura da realidade parte da significação que os sujeitos fazem da situação a ser estudada. A pesquisa e a problematização permitem a desconstrução e reconstrução desta significação. (BRASIL, 2014, p. 57)

Todas as atividades propostas tiveram como premissa o desvelar da realidade, ou melhor, de uma leitura da realidade. O diálogo foi a principal ferramenta nesse processo, no qual os educadores/pesquisadores eram mediadores e tinham por objetivo fazer emergir o conhecimento existente em cada sujeito.

O Projeto nasce de uma realidade constatada, qual seja, um grupo de trabalhadores que há anos sustenta as suas famílias como guias de turismo e por conta da regularização da profissão necessita se adequar concluindo um curso técnico, portanto, em nível de Ensino Médio. Como não possuem o Ensino Fundamental, a problemática aí se apresenta: esses trabalhadores que possuem trajetórias escolares descontínuas por terem que abandonar seus estudos pelos mais variados motivos possuem conhecimentos que podem ser reconhecidos pela escola? Há possibilidades de construção de conhecimentos nos espaços não formais de ensino? Enquanto a vida estava acontecendo longe dos bancos escolares e inserida no complexo mundo do trabalho houve aprendizagem passível de ser reconhecida pela escola? Acredita-se que sim e, desta forma, esse projeto toma vida.

\section{Aprendizagem criativa}

Num processo de construção coletiva pactuam-se propostas e ações com os diferentes sujeitos e em diferentes níveis de envolvimento. Reforça também a filiação, a vinculação, o sentimento de pertença, a coesão, o diálogo e o fortalecimento das diversas redes e organizações da sociedade civil, como também o diálogo contínuo e permanente com os governos. [...] O espaço de aprendizagem criativa também nos faz repensar a retomada do trabalho de base, essencial para fortalecer a organização social e a luta popular. (BRASIL, 2014, p. 58) 
A própria intenção do Projeto está pautada na aprendizagem criativa, e embora tenha como objetivo principal identificar saberes e não ensinar, não se pode negar que nessa busca pela identificação dos saberes a aprendizagem também acontece; isso ficou evidenciado nas atividades realizadas, que buscaram a criatividade coletiva, tanto nas experiências dos sujeitos quanto nas dos educadores.

\section{Orientações teórico-metodológicas para novas propostas}

“Caminhante, não há caminho, se faz caminho ao andar." Antônio Machado (1875-1939)

Apresentamos, para experiências semelhantes, alguns caminhos teóricometodológicos que detalhamos a seguir:

\section{Etapa 1 - Formando um grupo de trabalho}

"Não podia ser qualquer professor, tinha que acreditar [...]" Coordenação do Projeto Piloto

A formação da equipe não deve ser pensada somente como uma atividade técnica, de domínio dos passos do processo de reconhecimento e certificação, mas sim como uma prática reflexiva sobre o próprio sentido do trabalho a ser desenvolvido, sobre os princípios norteadores da prática pedagógica e do significado do reconhecimento e certificação de saberes para os estudantes trabalhadores.

A fala de uma das educadoras/pesquisadoras, dirigida aos trabalhadores ao final do processo, revela um pouco a natureza do trabalho que deve ser desenvolvido num processo de reconhecimento de saberes: O objetivo era que nós buscássemos despertar, mobilizar, motivar conceitos que vocês já tinham com vocês. Durante esses dias vocês descobriram que sabiam muitas coisas, que agora acham que aprenderam, mas, na verdade, já eram conhecimentos que acompanhavam vocês e que muitas vezes ficam adormecidos. 
É aconselhável que estes profissionais tenham experiência na EJA, em Educação Popular, e em Economia Solidária. No Relatório Final da V Plenária Nacional de Economia Solidária, em que mais de 10.000 trabalhadores debateram, a Economia Solidária está definida como "[...] um movimento social organizado e estratégia de desenvolvimento territorial, sustentável, diverso e solidário; movimento de opção de organização popular e luta emancipada de trabalhadores associados para o enfrentamento e superação do capitalismo." (HICKENBICK e FELÁCIO, p. 39, 2014).

De acordo com Hickenbick e Felácio (2014):

As condições sociais que fundamentam a existência da EJA apontam para a necessidade de uma prática educativa que pense a transformação das atuais condições de vida de grande parte da população brasileira, na qual se insere o público dessa modalidade de ensino. O ensino da Economia Solidária pode ser uma possibilidade para a concretização desta prática, que deve ser pensada como práxis, ou seja, como interpretação do mundo para a sua transformação. Em julho de 2012, o MTE, por meio da SENAES e do Conselho Nacional de Economia Solidária publicou a recomendação $n^{\circ} 8[. .$.$] que preconiza o ensino de Economia Solidária em$ todos os níveis de ensino, do Fundamental ao Superior e, especialmente, na EJA como tema transversal, assim como a formação dos profissionais da educação, para que o ensino possa realmente acontecer. [...] Os motivos pelos quais o documento destaca o ensino do tema na EJA estão diretamente relacionados ao perfil deste público, [...] o que impulsiona a ideia do ensino de Economia Solidária na Educação Básica é a busca pela emancipação do ser humano e pela superação da sociedade da exploração. (HICKENBICK e FELACIO, p.38 e 39, 2014)

Caso não seja possível a formação da equipe com este perfil, acredita-se que na Etapa dois o tempo de leituras e preparação precise ser mensurado de forma que estes possam dialogar com atores sociais que tenham estas experiências. A equipe deverá ser composta de pelo menos dois professores por disciplina, dois sistematizadores e um coordenador. Como pode ocorrer desistência durante o processo, é importante ter uma lista de pelo menos dois suplentes por disciplina . A prática da autogestão do grupo é indicada, sendo todas as decisões coletivas, respeitando o papel e compromissos de cada participante, preferencialmente registrado no plano de trabalho a ser elaborado, desde o início do processo. 
"Ler é sonhar pela mão de outrem."

Como referencial teórico metodológico, destacamos os PCNs (1997), o Marco de Referência da Educação popular Para Políticas Públicas (2014), o CERTIFIC (2009) e o Documento Base do PROEJA (2006). É certo que, a cada grupo formado, apresentam-se novas características e vivências, e, consequentemente, o surgimento de novas contribuições teóricas, adensando assim o referencial do projeto-piloto. Ressaltamos a importância do registro através de relatório estruturado das análises, debates e críticas do grupo a fim de se ter todo o processo documentado, contribuindo para o seu aperfeiçoamento.

\section{Etapa 3-Conhecendo o sujeito}

É fundamental que o grupo de educadores conheça os sujeitos que participarão do processo: seu cotidiano e expectativas. Estas informações auxiliarão a escolha das metodologias e dinâmicas de avaliação a serem propostas. Para isso, é importante elaborar instrumentos de coleta de dados, para a construção do perfil socioeconômico dos mesmos. Pode-se utilizar questionários, entrevistas, dinâmica de grupo. O primeiro contato entre o grupo certificador e os trabalhadores educandos deve proporcionar um espaço de acolhida, de encontro, de troca de experiências e de coleta de dados.

\section{Etapa 4 - Preparando um plano de avaliação e certificação}

"Tudo que está no plano da realidade já foi sonho um dia." Leonardo da Vinci

Nesta etapa, ao mesmo tempo em que os sistematizadores estruturam a apresentação do perfil socioeconômico dos sujeitos, os professores começam a estruturar suas propostas de atividades, de forma interdisciplinar ou por área de 
conhecimento. Devem ser construídos os instrumentos de diagnóstico, devendo constar os objetivos, justificativa e metodologia de cada atividade. Todas as propostas por área devem ser apresentadas em reuniões coletivas, sendo debatidas e aperfeiçoadas por todo o grupo e verificando a possibilidade da atividade envolver mais de uma disciplina. Nesta fase, identificam-se quais estratégias podem ser utilizadas de forma conjunta, sendo possível, e até aconselhável, que as dinâmicas sejam desenvolvidas coletivamente.

Nestes casos, mesmo se utilizando da mesma estratégia, os planos por disciplina devem expressar suas especificidades. É importante lembrar que não se trata de uma atividade de ensino e sim de reconhecimento de saberes, sendo necessária a utilização de um instrumento de avaliação concebido e padronizado pela equipe (Ver apêndice 1). Com o plano em mãos e o calendário fechado, começam as atividades de avaliação.

\section{Etapa 5-Reconhecendo os saberes}

"A coisa mais indispensável a um homem é reconhecer o uso que deve fazer do seu próprio conhecimento."

Platão

Este período é intenso, pois pressupõe encontros diários, sendo importante a reserva de pelo menos um dia da semana para reunião de avaliação da equipe. As atividades devem seguir o plano elaborado coletivamente, sendo constantemente avaliado e, se necessário, modificado. Recomenda-se que os docentes trabalhem em duplas para facilitar o registro nos instrumentos de avaliação. Em todas as atividades deve estar presente um sistematizador, que fará anotações mais gerais da atividade. Recomenda-se que seja prevista uma carga horária para que os integrantes do processo estruturem suas anotações logo após o encontro para que não sejam omitidas informações valiosas sobre o processo. Indica-se o registro fotográfico e, se possível, a filmagem de todas as atividades desenvolvidas.

A coordenação acompanha todas as atividades e se responsabiliza por questões estruturais e, além da organização geral dos materiais como lista de presença dos alunos 
e professores e documentos gerais, acompanha os resultados da sistematização, auxiliando na operacionalização junto aos setores institucionais pertinentes.

Ao final do processo, as disciplinas apresentam um diagnóstico de cada estudante trabalhador. Estes devem ser apresentados e debatidos coletivamente em uma reunião de avaliação em que será decidida a certificação ou não dos participantes.

Após esta etapa, cada participante recebe de um dos membros da equipe o certificado de Ensino Fundamental bem como o resultado final (avaliação descritiva) do processo. Nesse momento, é informado ao participante, numa conversa individual, suas fragilidades bem como o seu potencial para a continuidade de seus estudos.

\section{Analisando os objetivos}

Entre os trabalhadores certificados, seis eram parte do grupo já contatado e préinscrito no Curso Técnico em Guia de Turismo - , que iniciaria no semestre subsequente ao processo de reconhecimento de saberes. De acordo com o Documento Orientador para a EJA no IFSC - que se encontra em fase de elaboração - a busca ativa do público estratégico é fundamental em projetos para este público.

Diferente era a situação das seis trabalhadoras, cozinheiras das escolas da Rede Municipal de Educação de Florianópolis, que não integravam um projeto, mas poderiam, conforme mencionado anteriormente, ingressar na oferta regular anual do curso Proeja Técnico em Gastronomia.

Como havia o espaço de um semestre entre a finalização do Processo de Reconhecimento de Saberes e o início do curso técnico, as trabalhadoras foram aconselhadas a se matricular num curso de formação inicial e continuada (FIC) na área de panificação. Quatro delas assim o fizeram, sendo que duas se encontram, atualmente, cursando o Técnico em Gastronomia. Uma trabalhadora teve que voltar para o Rio Grande do Sul (disso soubemos na ocasião da entrega dos certificados, quando se emocionou ao afirmar a importância do projeto na sua vida e que voltaria a estudar na sua cidade natal); a sexta integrante, de mais idade, disse que um curso técnico não 
caberia atualmente, na sua vida, mas que iria procurar um curso de qualificação profissional por ter um prazo de duração menor.

Dos seis trabalhadores guias de turismo certificados, cinco foram fazer o curso Técnico em Guia, sendo que um deles não conseguiu articular os horários do emprego com os do curso, mas desejava fazê-lo.

Dos cinco, um abandonou no primeiro semestre por motivo de doença na família, desemprego e local de moradia extremamente distante da escola. Entre os quatro cursistas, um apresenta dificuldades acima da média da turma, o que já havia sido diagnosticado no processo de reconhecimento de saberes escolares.

A partir destes resultados, duas cozinheiras e quatro guias matriculados num curso Proeja Técnico, pode-se dizer que os objetivos que motivaram a realização desse projeto tenham sido alcançados, já que os objetivos eram: reconhecer saberes de trabalhadores em nível de Ensino Fundamental para possibilitar o seu acesso a um curso técnico (Nível Médio).

Todos dos trabalhadores que participaram do projeto indicaram - e até realizaram ações nesse sentido - que gostariam de continuar estudando, quer seja num curso técnico, quer seja num curso de qualificação profissional em que a escolaridade em nível de Ensino Fundamental nem sempre é um pré-requisito.

Então cabe a reflexão: o projeto foi pensado, inicialmente, para atender aos guias de turismo, com os quais a instituição já mantinha contato desde 2013. A possibilidade de ampliar o universo de pessoas atendidas pelo projeto, no caso as cozinheiras, veio depois, na perspectiva da otimização de recursos públicos. Ora, entre os guias, considera-se que o projeto atingiu totalmente o seu objetivo, uma vez que todos manifestaram interesse em ficar na instituição para concluir o curso técnico, embora dois deles não o tenham conseguido pelas contingências da vida adulta, ou seja, pela inadequação de um espaço escolar capaz de atender as especificidades de adultos trabalhadores. Essa realidade nos remete à fala de Kruppa (2005) "Uma das explicações para o freio conservador da escola está em seu isolamento da realidade. Envolta pela rotina e fechada em muros, a escola 
não tem sensibilidade para o movimento da vida, distante dos problemas e das alternativas que a população cria para sobreviver" (KRUPPA, 2005, p. 22).

Já em relação às cozinheiras, que não participaram dos diálogos para a construção do projeto, e pouco sabiam de seu propósito ao se vincular a ele, pode-se dizer que atingiram outros objetivos, os delas, expressos em suas falas, não os pensados por quem concebeu o projeto. Isso nos faz lembrar a fala de Freire (2005):

Não seriam poucos os exemplos que poderiam ser citados, de planos, de natureza política ou simplesmente docente, que falharam porque os seus realizadores partiram de uma visão pessoal da realidade. Porque não levaram em conta, num mínimo instante, os homens em situação a quem se dirigia seu programa, a não ser por puras incidências de sua ação. (FREIRE, 2005, p. 97 e 98)

A citação de Freire ratifica a importância de se ouvir os sujeitos quando se deseja construir projetos para atender a estes sujeitos. O autor escreve sobre o fracasso de projetos que não levaram em conta a realidade do sujeito. No caso dessa pesquisa, a realidade dos sujeitos foi levada em conta, porém o que foi revelado, o que foi despertado em cada um é que surpreendeu, pois superou o que os idealizadores do projeto tinham como meta: reconhecer que esses trabalhadores estariam aptos a cursar um curso de Ensino Médio na modalidade EJA. O que se presenciou, no entanto, ultrapassou essa meta: presenciou-se o descortinar de um novo mundo para estas pessoas, como podemos verificar nas falas de três trabalhadoras:

Trabalhadora 3: Para mim esses dias aqui não são dias comuns. Saber que o mundo não é tão pequenininho como parece ser quando a gente está lá dentro de casa. Abrir um mundo. Abrir uma janela, uma porta, e você ver bem além do que está vendo. É só a gente querer mesmo

Trabalhadora 4: É muito importante que eu tenha aula. Os meus filhos nunca me mostraram deveres. Eles começaram a me mostrar. Então, eu vejo que eu fui exemplo. Eu sou exemplo. 
Trabalhadora 5: Uma injeção de ânimo... Para mim foi de autoestima, porque eu pensei que não era nada e hoje eu sei que sou. Demorou um tempo, mas aprendi bastante coisa...Parece que me tiraram do meio do nada, da minha casinha, e me colocaram no meio da cidade.

Entretanto, ainda que o projeto tenha sido relevante para as trabalhadoras, reafirma-se a relevância da vinculação a uma demanda específica, no momento da busca ativa de um público de EJA, momento em que também se inicia a relação do potencial aluno com a instituição, com outras palavras, o trabalho de extensão.

Com relação aos limites e dificuldades na proposição do projeto, os resultados nos permitem apontar algumas questões:

Em termos de cronograma de execução, conforme já mencionado, há que se dedicar mais tempo à preparação da equipe de educadores/pesquisadores. Seria, ainda, extremamente importante a previsão de acompanhamento sistemático dos egressos, tanto os que ingressaram em cursos, quanto os que não ingressaram.

Entre os que ingressaram, retoma-se a questão do conhecimento real e do conhecimento potencial, presente no PCNs. Um dos estudantes, claramente, está na categoria de conhecimento potencial, necessitando de um acompanhamento que a instituição não tem tido condições de atender.

Ressalta-se que houve uma tentativa de retomada do Projeto, por parte da Coordenação na Pró-reitoria de Ensino, para dar conta destas questões, tanto no que se refere ao aprofundamento teórico, quanto ao acompanhamento dos egressos. Mas, dificuldades quanto à formação da equipe, em primeiro lugar, somadas a questões orçamentárias, impossibilitaram a iniciativa.

\section{Considerações Finais}

É importante retomar o objetivo principal deste projeto, para então afirmar que a sua proposição teve êxito, que valeu a pena. 
Este objetivo deve ser retomado tanto pela sua dimensão de pautar, no IFSC, o reconhecimento de saberes escolares em nível de Ensino Fundamental de trabalhadores, potenciais alunos de cursos de nível médio, quanto pela sua dimensão de efetivamente promover o ingresso de um grupo de estudantes trabalhadores na educação profissional, na modalidade de EJA.

O projeto foi exitoso, valeu a pena, porque se evidenciaram questões importantes para uma instituição que tem como objetivo, explicitamente colocado na Lei de sua criação, a inclusão social.

Uma destas questões diz respeito justamente à inclusão de parcela significativa da nossa sociedade que não teve o seu direito à educação atendido.

Consideramos extremamente importante reafirmar que a escola não dá conta de corrigir esta situação, porque ela está relacionada a uma estrutura social excludente. Uma questão se impõe: quanto pode a escola diante da vida de quem precisa - desde muito cedo - sustentar a família, e portanto tem que usar o seu tempo para trabalhar ou buscar emprego? Por outro lado, a escola, que não foi pensada para atender as especificidades da vida de um adulto, de um trabalhador, não pode ser passiva; precisa buscar atenuar as imensas dificuldades que o público da EJA encontra para retornar à escola.

Desta forma, é preciso que se reafirme a necessidade de subsídio institucional para a oferta de EJA, formada por pessoas para as quais "a escola não é uma escolha natural, pelas dificuldades que se farão presentes ao se fazer esta escolha, ao mesmo tempo em que a sociedade exige a sua escolarização" (RAMOS, HICKENBICK, 2015, p. 1).

É preciso garantir institucionalmente o acompanhamento de estudantes trabalhadores, egressos ou não de processos de reconhecimento escolares, para dar conta de uma das constatações do presente projeto, qual seja, o fato de que esses sujeitos detêm conhecimentos potenciais, mais que conhecimentos reais, e, sem atendimento individual, sucumbem.

O subsídio institucional deve ser visto no sentido de buscar um equilíbrio entre a oferta para sujeitos que já chegam à escola com mais autonomia, e, portanto, garantem acesso e permanência mais facilmente (e aí temos então, as turmas numerosas, os 
números, dos quais também temos que dar conta), e a oferta de EJA, esta composta por sujeitos que ainda buscam a sua autonomia, visto que não têm o manejo da cultura da escola.

Deve-se ainda pensar o subsídio pautando a formação dos professores, uma formação voltada para a educação popular, para que tenhamos mais mestres e doutores dispostos a pensar o conhecimento de forma mais ampla, para além da sua área de formação específica.

Tal Instituição ainda não existe, e contra o seu nascimento estão os estatísticos, com análises quantitativas, sempre à mão, a demonstrar o quanto somos ineficientes na oferta para este público. E os mestres e doutores - alguns especialistas em sujeito EJA -, a discorrer sobre a impossibilidade de ensinar para estes sujeitos.

Quando esta instituição existir, deverá considerar as palavras de Kaká Werá Jacupé, índio e liderança guarani, da aldeia Morro da Saudade (São Paulo), que citando o monge tibetano Dalai Lama, nos ensina que "o mundo possui muitas mentes brilhantes, mas hoje o mundo precisa de corações brilhantes."

\section{Referências}

AlBUQUERQUe, Paulo Peixoto de. Autogestão. In: CATTANI, A. D. (Org.). A outra economia. Porto Alegre: Veraz Editores, 2003. p. 20-25.

BERGER, Daniel Godinho, HICKENBICK, Claudia e RAMOS, Elenita Eliete de Lima - Projeto de extensão: projeto piloto de reconhecimento e certificação de saberes escolares de trabalhadores da área de turismo, hospitalidade e lazer. Florianópolis: IFSC, 2014.

BRASIL. Parâmetros curriculares nacionais ensino fundamental. Brasília, DF: MEC, [1997]. Disponível em<portal.mec.gov.br/seb/arquivos/pdf/introducao.pdf > Acesso em: 01 abr. 2014.

BRASIL. Ministério da Educação. Programa Nacional de Integração da Educação Profissional com a Educação Básica na Modalidade de Educação de Jovens e Adultos Documento Base. Brasília, DF: MEC, 2007. Disponível em: < http://portal.mec.gov.br/setec/arquivos/pdf2/proeja_medio.pdf>. Acesso em: 12 abr. 2014. 
BRASIL. Secretaria Nacional de Articulação Social. Marco de referência da educação popular para as políticas púbicas. Brasília, DF: MEC, 2014. Disponível em: < http://conae2014.mec.gov.br/images/pdf/MarcodeReferencia.pdf> Acesso em jul. 2014.

BRASIL. Ministério da Educação e Ministério do Trabalho e Emprego. Documento orientador da rede nacional de certificação profissional e educação continuada Certific. Brasília, DF: MEC, 2009. Disponível

em:<http://portal.mec.gov.br/index.php?option=com_content\&view=article\&id=15266\&lt emid $=800>$ Acesso em: 12 agost. 2015.

BRASL. Ministério da Educação e Ministério do Trabalho e Emprego. Portaria Interministerial n. 5 de 25 de abril de 2014. Disponível em:

<http://www.legisweb.com.br/legislacao/?id=269742> Acesso em: 12 dez. 2014.

CISNEROS, Leandro Marcelo. Ensino de Filosofia para uma Educação do Campo: uma experiência em assentamentos do MST no interior de Santa Catarina. In: BOEMER. Leyli, Abdala Pires, et al. (Org.). Escola e vida: uma experiência pedagógica de estudo por complexos em assentamentos do MST no Estado de Santa Catarina. Florianópolis: Insular, 2013.

CUNHA, Daisy Moreira; LIMA Natália Valadares. Reconhecimento e certificação de saberes construídos no ambiente de trabalho: uma análise comparada dos dispositivos inglês e brasileiro. In: $5^{\circ}$ Encontro Internacional de Educação Comparada. Avaliação do rendimento escolar: dimensões internacionais, 2012, Belém. Disponível em: <http://www.sbec.org.br/evt2012/trab11.pdf> Acesso em: 24 set. 2014.

DALMAGRO, Sandra. MOURA, Ezequiel Antônio de. A experiência pedagógica com os complexos de estudo no curso de Ensino Médio EJA Pronera UFSC Disponível em: <http://www.vanessanogueira.info/sifedoc/Anais/Eixo\%2004/Sandra\%20Luciana\%20Dalma gro.pdf $>$ e <http://coral.ufsm.br/sifedocregional/images/Anais/Eixo\%2004/Sandra\%20Luciana\%20Dalm agro.pdf> Acesso em 01 abr. 2014.

ENGEL, Guido. Irineu. Pesquisa-ação. Educar, Curitiba, n.16, p. 181-191, 2000. Disponível em:<file:///C:/Users/Usuario/Desktop/documentos/ATIVIDADES\%20PROFISSIONAIS/IFSC/P ROJETO/artigo/irineu_engel\%20artigo\%20sobre\%2opesquisa\%20a\%C3\%A7\%C3\%A30\%202.pdf > Acesso em: 19 nov. 2014 .

FISCHER, Maria Clara Bueno; FRANZOI, Naira Lisboa. Formação humana e educação profissional: diálogos possíveis. Educação, Sociedade e Culturas, n. 29, 2009, p.35-51 Disponível em: <www.fpce.up.pt/ciie/revistaesc/ESC29/29ClaraFNairaF.pdf > Acesso em 06 fev. 2014 . 
FREIRE, Paulo. Conscientização: teoria e prática da libertação. 3 ed. São Paulo: Centauro, 2006.

FREIRE, Paulo. Pedagogia do oprimido. 46. ed. São Paulo: Paz e Terra, 2005.

HICKENBICK, Claudia. FELÁCIO, Rafael Matos. Economia solidária e arranjos produtivos locais. Florianópolis: IFSC, 2014.

INSTITUTO FEDERAL DE EDUCAÇÃO, CIÊNCIA E TECNOLOGIA DE SANTA CATARINA. Relatório do projeto piloto de reconhecimento e certificação de saberes escolares de trabalhadores da àrea de turismo, hospitalidade e lazer, Florianópolis: IFSC, 2014.

KRUPPA, Sonia M. Portella (Org.). Economia solidária e educação de jovens e adultos. Brasília: Inep, 2005.

RAMOS, Elenita Eliete de Lima. Propondo práticas e desafiando certezas: um estudo em turma do PROEJA numa perspectiva de educação matemática crítica. 2011, 301F. Tese Universidade Federal de Santa Catarina, Doutorado em Educação Científica e Tecnológica, Florianópolis, 2011.

RAMOS, Elenita Eliete de Lima. HICKENBICK, Projeto formativo para a EJA: a integração entre processo educativo e prática social na educação profissional. In: CONGRESSO NACIONAL DE PROGRAMAS EDUCATIVOS PARA JOVENS, ADULTOS E IDOSOS. 1. , 2015, Campos dos Goytacazes. Anais...Campos dos Goytacazes, 2015.

SOARES, Leôncio; GIOVANETTI, Maria Amélia Gomes de Castro; GOMES, Nilma Lino. Diálogos na educação de jovens e adultos. Belo Horizonte: Autêntica, 2007.

STEFFEN, Euli Marlene. Sistema de certificação de competências no Brasil e em Portugal. Trabalho \& Educação, v.18, n. 1, jan./abr. de 2009. Disponível em:< http://www.portal.fae.ufmg.br/seer/index.php/trabedu/article/viewFile/401/466> Acesso em: 24 set. 2014. 
Apêndice 1 - modelo de instrumento de diagnóstico utilizado no projeto piloto

\begin{tabular}{|c|c|c|c|c|}
\hline \multicolumn{5}{|l|}{ ARTES } \\
\hline \multicolumn{5}{|l|}{ Nome do aluno } \\
\hline & \multicolumn{4}{|c|}{ Diagnóstico } \\
\hline Oficinas & Sim & Não & Parcial & Observações \\
\hline \multicolumn{5}{|l|}{ Oficina 1: Relato de Experiência } \\
\hline $\begin{array}{l}\text { Objetivo 1: Identificar produtos e } \\
\text { procedimentos artísticos expressos em } \\
\text { várias linguagens da arte; }\end{array}$ & $x$ & & & Chegada tardia \\
\hline $\begin{array}{l}\text { Objetivo 2: Reconhecer diferentes } \\
\text { padrões artísticos e estéticos } \\
\text { associando-os ao seu contexto social e } \\
\text { histórico; }\end{array}$ & $x$ & & & \\
\hline $\begin{array}{l}\text { Objetivo 3: Relacionar a sua identidade } \\
\text { com a produção cultural da cidade; }\end{array}$ & & & & $\begin{array}{l}\text { Produção escrita } \\
\text { muito breve }\end{array}$ \\
\hline \multicolumn{5}{|l|}{ Oficina 2: Saída de Estudos } \\
\hline $\begin{array}{l}\text { Objetivo 1: Utilizar os conhecimentos } \\
\text { sobre a relação entre arte e realidade, } \\
\text { para atribuir sentido para uma } \\
\text { expressão artística; }\end{array}$ & $x$ & & & \\
\hline $\begin{array}{l}\text { Objetivo 2: Expressar através da } \\
\text { linguagem visual, apropriando-se de } \\
\text { símbolos e elementos da visualidade; }\end{array}$ & $x$ & & & \\
\hline $\begin{array}{l}\text { Objetivo 3: Utilizar instrumentos e } \\
\text { procedimentos na produção de } \\
\text { imagens e organização do espaço } \\
\text { visual; }\end{array}$ & & & & $\begin{array}{l}\text { Resultado satisfatório } \\
\text { na segunda atividade }\end{array}$ \\
\hline \multicolumn{5}{|l|}{ Oficina 3: Comunicação e leitura visual } \\
\hline $\begin{array}{l}\text { Objetivo 1: Perceber a influência da } \\
\text { publicidade em suas vidas e as possíveis } \\
\text { leituras em diferentes épocas e }\end{array}$ & & & $x$ & Faltou \\
\hline
\end{tabular}




\begin{tabular}{|c|c|c|}
\hline situações tecnológicas; & & \\
\hline $\begin{array}{l}\text { Objetivo 2: Posicionar-se criticamente } \\
\text { sobre os valores sociais e estéticos } \\
\text { presentes na cultural visual; }\end{array}$ & $\mathrm{X}$ & $\begin{array}{l}\text { A observação foi feita } \\
\text { parcialmente em } \\
\text { outro momento }\end{array}$ \\
\hline
\end{tabular}

\section{Parecer descritivo:}

A observação e a análise sistemática das ações permitem diagnosticar que o educando possui capacidades de ordem cognitiva em se expressar na linguagem das artes visuais, apropriando-se de códigos e símbolos para atribuir significados na construção de seu próprio olhar sensível. Reconhece as manifestações artísticas como produtos da cultura e as relacionada às experiências de sua vida.

O educando apresentou algumas dificuldades relacionadas na participação na oralidade em situações de atividades de debate coletivas. Também, a expressão escrita é muito breve, fator que limitou observar partes do diagnóstico. Nos aspectos formativos, salienta-se dificuldade no compromisso com horário. Entretanto, demonstra conhecimentos reais e potenciais para dar continuidade aos estudos com relação à disciplina de artes. 